\title{
Development of the VMS Emulator System
}

\author{
Jung-Sook Kim \\ Division of IT, Kimpo College, Gimpo-si, Geyonggi-do, Korea \\ kimjs@kimpo.ac.kr
}

\begin{abstract}
A variable message signs is an electronic traffic sign often used on roadways to give travelers information about special events. However, a variable message signs has the different sizes and a specific type according to the city scene and it has to be displayed by different message on the display panels in real-time. And the variable message signs providers must produce the different products each order. In addition that, they should test and check the correct operation to each variable message signs product using different message frame. That is very time and workers consuming and automatic variable message frame generator system for variable message signs is necessary. In this paper, we design and implement an emulator system for variable message signs. The exact message size is decided when the message is generated. And the variable message generator can decide the exact message size using the difference between a given data size and a field of the data size. The system can be set several parameters easily on a window dialog which are necessary parameters for generating the variable message frame.
\end{abstract}

Keywords: Emulator system, Automatic variable message generator system, Variable message signs (VMS), Intelligent transportation system (ITS), Real-time

\section{Introduction}

Intelligent transportation systems (ITS) are advanced applications which, without embodying intelligence as such, aim to provide innovative services relating to different modes of transport and traffic management and enable various users to be better informed and make safer, more coordinated, and 'smarter' use of transport networks. To be effective, an intelligent transportation system must provide the correct real-time traffic-related information using a variable message signs. A variable message sign, often abbreviated VMS, is an electronic traffic sign often used on roadways to give travelers information about special events. Such signs warn of traffic congestion, accidents, incidents, roadwork zones, or speed limits on a specific highway segment. In urban areas, VMS are used within parking guidance and information systems to guide drivers to available car parking spaces. They may also ask vehicles to take alternative routes, limit travel speed, warn of duration and location of the incidents or just inform of the traffic conditions. The information comes from a variety of traffic monitoring and surveillance systems. It is expected that by providing real-time information on special events on the oncoming road, VMS can improve vehicles' route selection, reduce travel time, mitigate the severity and duration of incidents and improve the performance of the transportation network [1-6]. However, VMS has the different sizes and shapes according to the city scene and it has to be displayed by different message on the display panel in real-time. And VMS providers have to produce the different products each order. In addition that, they should test and check the correct operation to each VMS product using different message frame. But, they don't have the test data and they must go an operational data center or a transport agency to get the test data. That is very time and workers consuming and automatic variable message generator system for VMS is necessary. In this paper, we design and implement 
the emulator system for variable message frame which can set several parameters easily on the Windows environment and the manufacturer of VMS do not need to go the field or data center to get the test variable message frame. The emulator system for variable message signs is composed of client/server model. The client is various information services panel such as VMS and PMS and the server is for controlling the system and it has the seven functions which are a message processor, a message generator, a message sender, a job configurator, a job scheduler, a message configurator, and a message logger.

The structure of this paper is as follows. Section 2 briefly introduces related studies. Section 3 describes the VMS emulator system and Section 4 presents its implementation and results details. Finally, the conclusions are drawn and the future study is discussed in Section 5.

\section{Related Works}

\subsection{Intelligent Transportation Systems}

Intelligent transportation systems (ITS) are advanced applications which, without embodying intelligence as such, aim to provide innovative services relating to different modes of transport and traffic management and enable various users to be better informed and make safer, more coordinated, and 'smarter' use of transport networks. Although ITS may refer to all modes of transport, EU Directive 2010/40/EU (7 July 2010) defines ITS as systems in which information and communication technologies are applied in the field of road transport, including infrastructure, vehicles and users, and in traffic management and mobility management, as well as for interfaces with other modes of transport. Intelligent transport systems vary in technologies applied, from basic management systems such as car navigation; traffic signal control systems; container management systems; variable message signs; automatic number plate recognition or speed cameras to monitor applications, such as security CCTV systems; and to more advanced applications that integrate live data and feedback from a number of other sources, such as parking guidance and information systems; weather information; bridge de-icing (US deicing) systems; and the like. Additionally, predictive techniques are being developed to allow advanced modelling and comparison with historical baseline data. Recent advances in vehicle electronics have led to a move towards fewer, more capable computer processors on a vehicle. A typical vehicle in the early 2000s would have between 20 and 100 individual networked microcontroller/Programmable logic controller modules with non-real-time operating systems. The current trend is toward fewer, more costly microprocessor modules with hardware memory management and Real-Time Operating Systems. The new embedded system platforms allow for more sophisticated software applications to be implemented, including model-based process control, artificial intelligence, and ubiquitous computing. Perhaps the most important of these for Intelligent Transportation Systems is artificial intelligence [1].

\subsection{Variable Message Signs}

A variable- (also changeable-, electronic-, or dynamic-) message sign, often abbreviated VMS, CMS, or DMS, and in the UK known as a matrix sign, is an electronic traffic sign often used on roadways to give travelers information about special events. Such signs warn of traffic congestion, accidents, incidents, roadwork zones, or speed limits on a specific highway segment. In urban areas, VMS are used within parking guidance and information systems to guide drivers to available car parking spaces. They may also ask vehicles to take alternative routes, limit travel speed, warn of duration and location of the incidents or just inform of the traffic conditions. A 
complete message on a panel generally includes a problem statement indicating incident, roadwork, stalled vehicle etc.; a location statement indicating where the incident is located; an effect statement indicating lane closure, delay, etc. and an action statement giving suggestion what to do traffic conditions ahead. These signs are also used for AMBER Alert and Silver Alert messages. In some places, VMSes are set up with permanent, semi-static displays indicating predicted travel times to important traffic destinations such as major cities or interchanges along the route of a highway. The information comes from a variety of traffic monitoring and surveillance systems. It is expected that by providing real-time information on special events on the oncoming road, VMS can improve vehicles' route selection, reduce travel time, mitigate the severity and duration of incidents and improve the performance of the transportation network [2].

\section{VMS Emulator System}

\subsection{System Structure}

The emulator system for variable message signs is composed of client/server model. The client is various information services panel such as VMS and PMS and the server is for controlling the system and it supports the seven functions which are a message processor, a message generator, a message sender, a job configurator, a job scheduler, a message configurator, and a message logger. The following Figure 1 show the emulator system structure

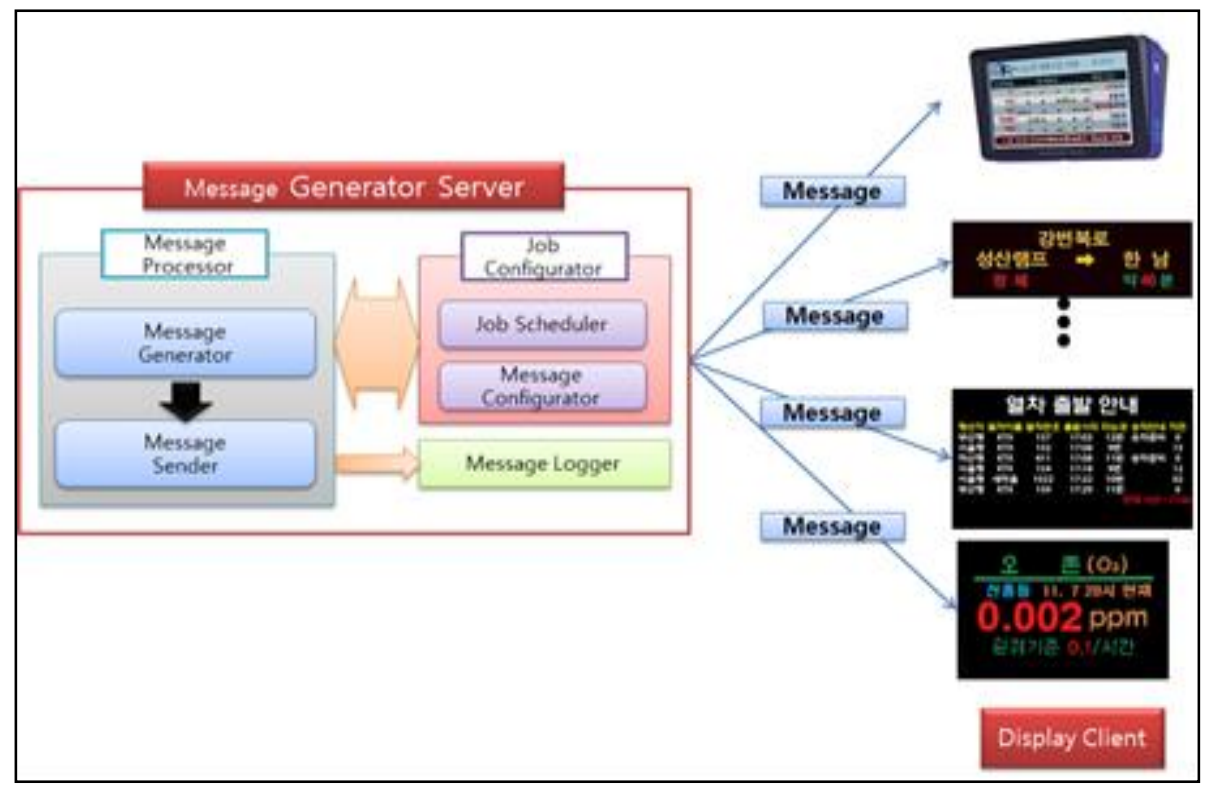

Figure 1. System Structure 


\subsection{Emulator System}

The following Figure 2 shows the variable message frame examples. In order to generate the variable message frame, we must get the data field $\mathrm{N}$ correctly from the given message frame. As you can see the Figure 2, the second message frame presents 2 bytes for data field but the forth message frame is 4bytes. The exact message size is decided when the message is generated. And the variable message generator can decide the exact message size using the difference between a given data size and a field of the data size. To be effective, a VMS must communicate a meaningful message that can be read and understood by motorists within a very short time period. And message design involves recognition of the basic principles for the following: 1) Message content refers to specific information displayed on a VMS. 2) Message length refers to rather the number of words or the number of characters and spaces in a VMS message. 3) Message load refers to the amount of information in the total message, usually expressed in terms of units of information. 4) Unit of informational refers to the answer to a question a motorist might ask. 5) Message format refers to the order and arrangement of the units of information on a VMS [2].

\begin{tabular}{|c|c|c|c|c|c|c|}
\hline $16 \mathrm{bith}$ & 16 byth & 2lith & What & 4hyth & 1hin & What \\
\hline SWOLRP & ostwanoN" & $\begin{array}{c}\text { cownoute } \\
\text { NeO }\end{array}$ & 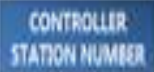 & Toths Lingth & oxcot & DATAFA: \\
\hline
\end{tabular}

\begin{tabular}{|c|c|c|c|c|c|c|c|}
\hline 1hen & 15 & 15 & 19 & itha & $\mathrm{k}$ 荫 & $2 \mathrm{ln}$ & it bit \\
\hline $\sin x$ & OKOOK & FAME NSMU:R & 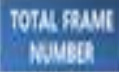 & DATAQTE & OATA & 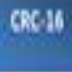 & ITX \\
\hline
\end{tabular}

\begin{tabular}{|c|c|c|c|c|c|c|c|}
\hline $1 \mathrm{kt}$ & $10 \mathrm{kth}$ & 20 & 1 ijw & M Hith & 1 bit & $10 \mathrm{w}$ & $2 \mathrm{kth}$ \\
\hline Dtt & $\sin$ & ADDR & okcot & DATA FIL & off & tix & C.C.1 \\
\hline
\end{tabular}

\begin{tabular}{|c|c|c|c|c|c|c|c|c|c|c|}
\hline $2 \mathrm{tin}$ & $10 \mathrm{BH}$ & $24 h$ & 2 hit & $1 \mathrm{ban}$ & $1 \mathrm{Hin}$ & 4 Bits & $7 \mathrm{mon}$ & 16 & $25+4$ & Ity \\
\hline $87 x$ & LeCL10 & $\begin{array}{c}\text { nami } \\
10\end{array}$ & $\begin{array}{l}\text { TOTA } \\
\text { BAMTINO }\end{array}$ & OKCOOL & oxoot & GATASEO & 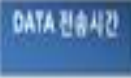 & VOATA & coses & $5 x$ \\
\hline
\end{tabular}

\begin{tabular}{|c|c|c|c|c|c|}
\hline Illyte & 1 ba & Ithen & 1 bith & abth & Noth \\
\hline FoW CONTEO & 02000 & stopera wo & A & OATA LINGTH & DAFA \\
\hline
\end{tabular}

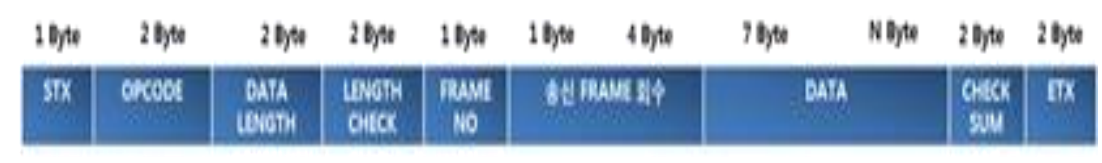

Figure 2. Example of the Variable Message Frame

The VMS are playing increasingly important roles in attempts to improve highway safety, operations, and use of existing facilities. VMSs are traffic control devices used for traffic warning, regulation, routing and management, and are intended to affect the 
behavior of drivers by providing real-time traffic-related information. The real-time information not only benefits individual drivers and the responsible transportation agency, but also the general public. Motorists are interested in reaching their destinations as safely as possible without undue delays. The transportation agency is interested in utilizing the available highway capacity of the corridor or network and to improve safety and mobility. The general public desires satisfaction of its demands for safe transportation with the least possible adverse environmental impacts due to noise and air pollution. And VMSs are programmable traffic control devices that can usually display any combination of characters to present messages to motorists. The following Figure 3 shows an example flowchart of the variable message signs operational procedure.

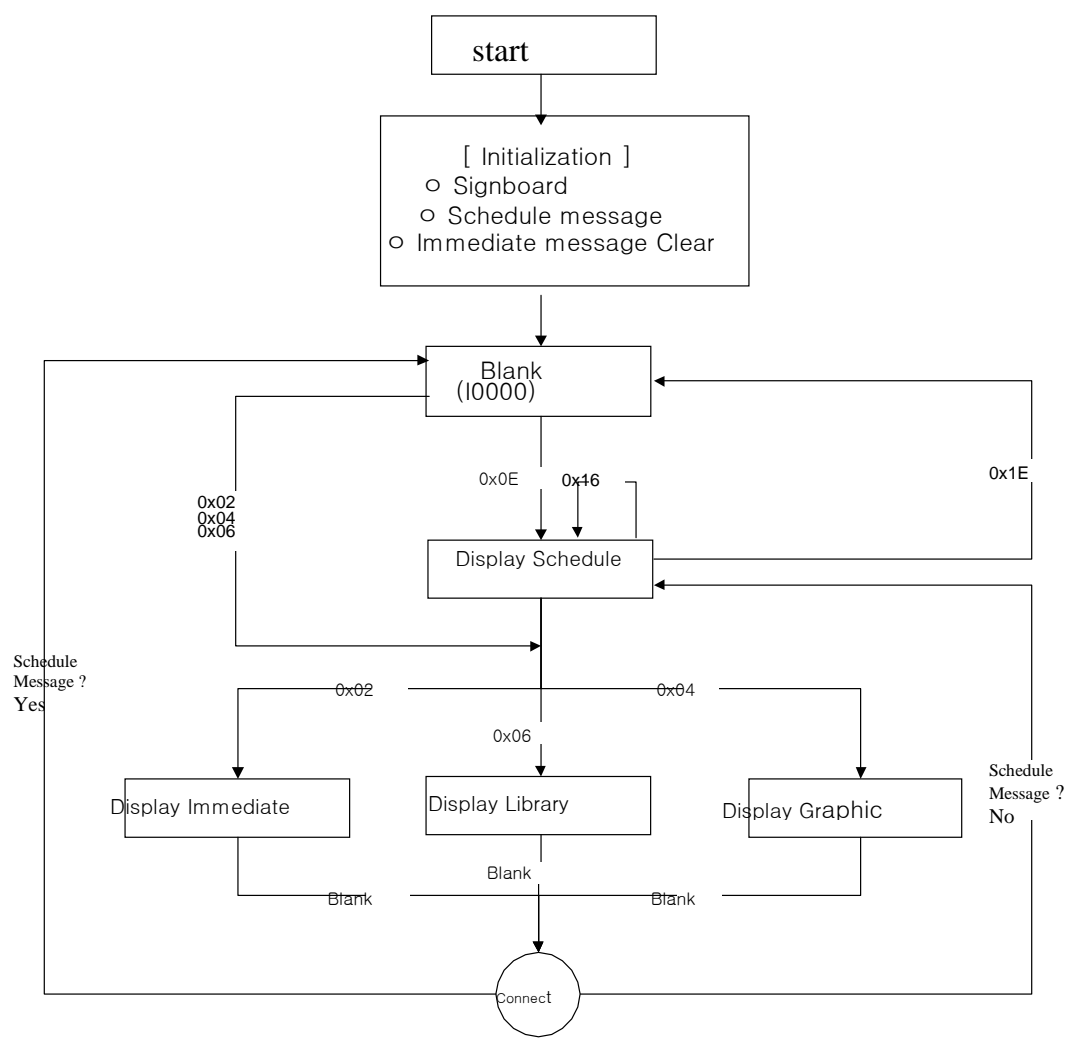

Figure 3. An Example Flowchart of a VMS Operational Procedure

\section{Implementation and Results}

We have implemented a VMS emulator system to generate the variable message frame. Since the signs represent the primary concept of intelligent transportation systems to motorists, improperly designed or operated VMS messages will have a negative impact on the perception of the public about intelligent transportation systems in general. The design and display of messages on VMSs introduce many challenges to transportation agencies. The Figure 4 shows a window dialog for setting the parameters to generate the variable message frame efficiently. This is for BIS (Bus Information System). 


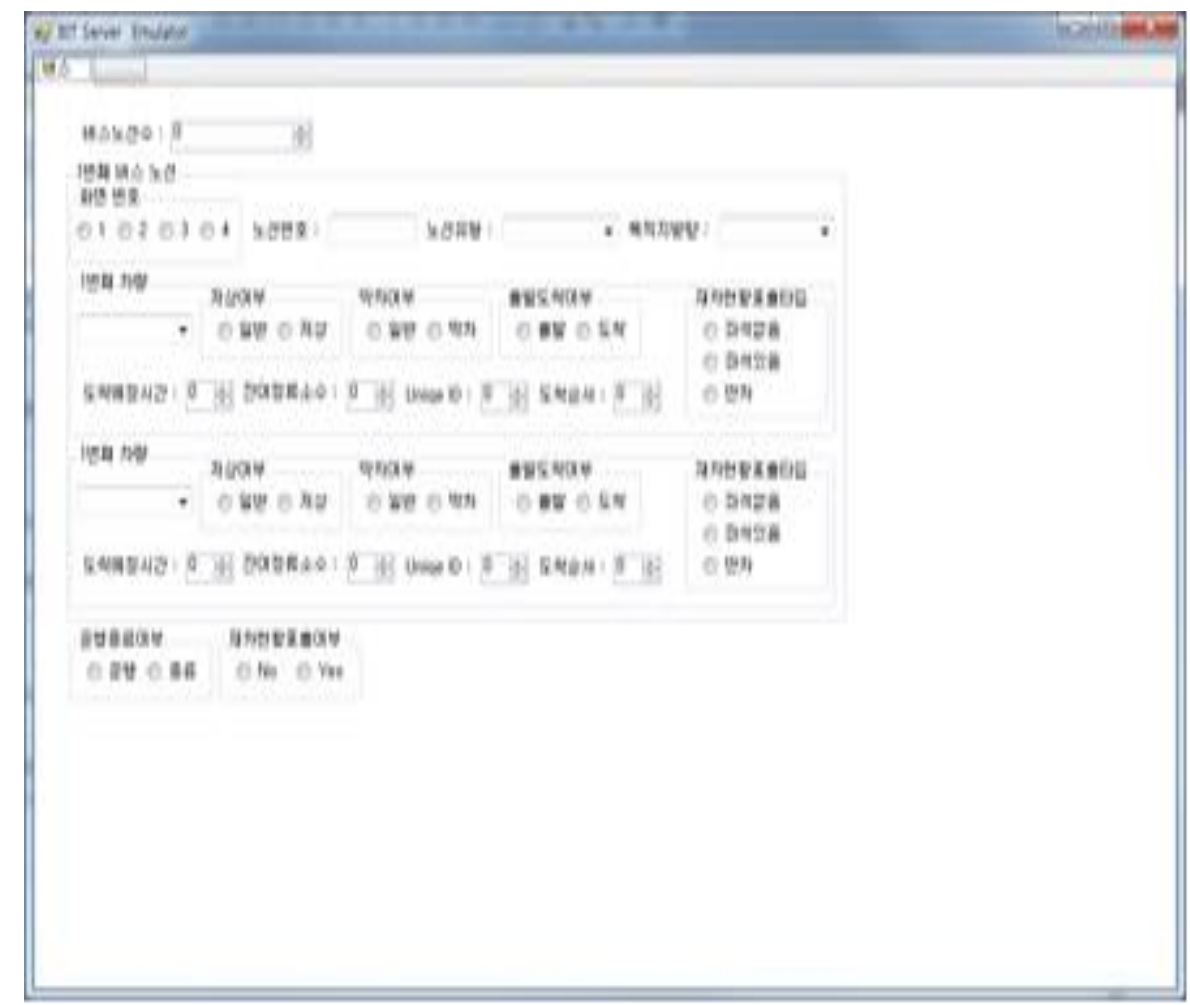

Figure 4. A parameter Setting Window

Permanently mounted VMSs are used primarily for the following applications: Caused by random, unpredictable incidents such as crashes, stalled vehicles, spilled loads; or caused by temporary, preplanned activities such as construction, maintenance, or utility operations; Caused by acts of nature such as fog, floods, ice, snow, and etc; Problems associated with special events; Operational features such as high occupancy, reversible, exclusive or contraflow lanes and certain design features such as drawbridges, tunnels, ferry services. VMSs can be an effective tool for communicating with motorists. However, displaying messages that are too long for motorists to read at prevailing highway speeds or that are too complex or inappropriately designed leading to motorist confusion, can adversely affect both traffic flow and the transportation agency's credibility. Also, for a specific type and design of VMS, the available message exposure time dictates the maximum length of message that can be displayed for a given highway operating speed. As you can see Figure 5, you can generate the variable message frame automatically and easily because you just put several parameters and click the buttons in a window dialog which is for setting the parameters. As a result, the variable message frame is generated what you want to be. 


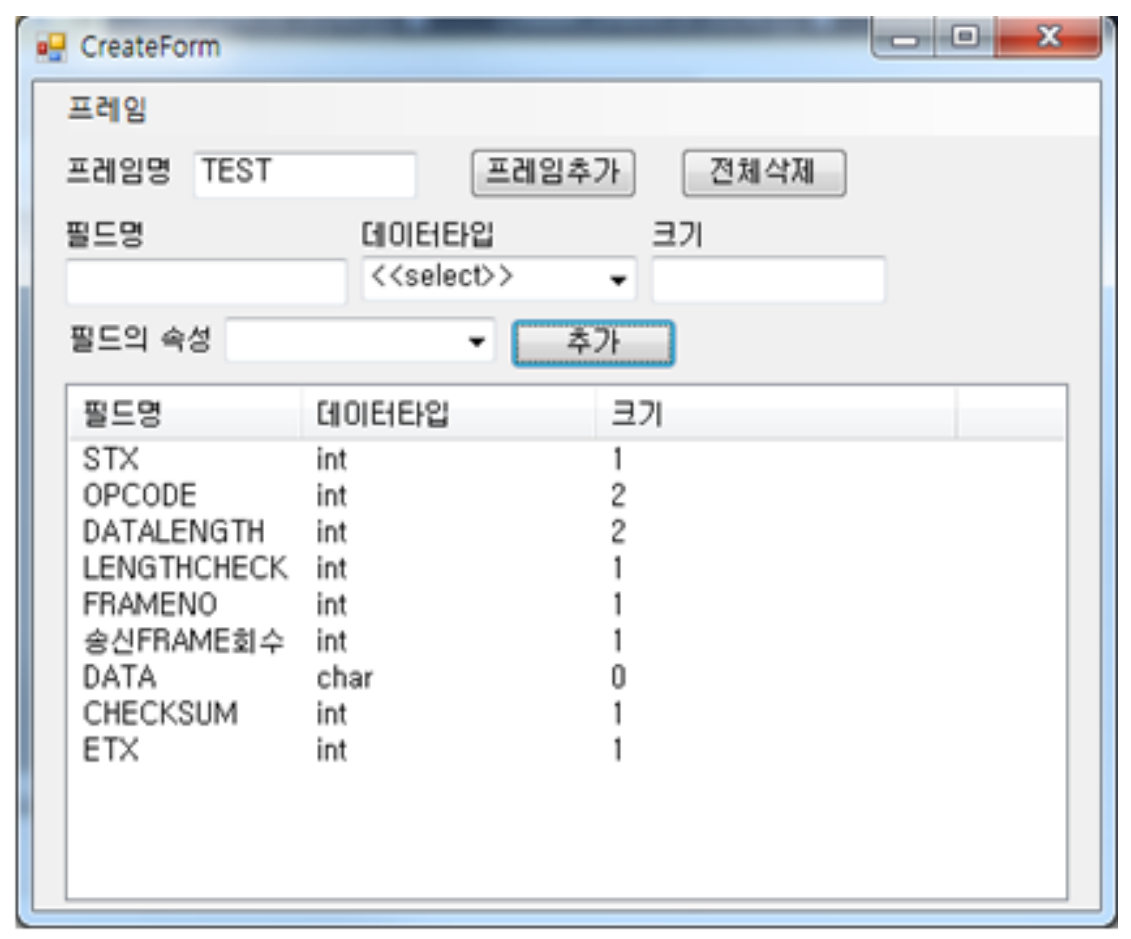

Figure 5. A Window Dialog for a Message Frame Parameter Setting

The Figure 6 shows the data fields in a table of database for generating variable message frame. If you put the parameters into the Figure 5 window dialog, then the input data is stored in a database as you can see in Figure 6.

\begin{tabular}{|c|c|c|c|c|}
\hline \multicolumn{4}{|c|}{ Createform } & \multirow[t]{2}{*}{\begin{tabular}{|l|l|l|}
0 & 回 & $x$ \\
\end{tabular}} \\
\hline \multicolumn{4}{|l|}{ 프레임 } & \\
\hline \multirow[t]{2}{*}{ 프례 } & test & $\nabla$ & 생성 & \\
\hline & 필드명 & 타입 & 크기 & 데이터 \\
\hline \multirow[t]{9}{*}{ 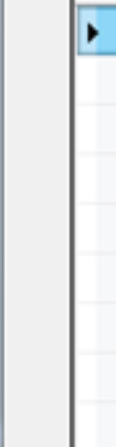 } & STX & int & 1 & \\
\hline & OPCODE & int & 2 & \\
\hline & DATALENGTH & int & 2 & \\
\hline & LENGTHCHECK & int & 1 & \\
\hline & FRAMENO & int & 1 & \\
\hline & 송신FRAME회수 & int & 1 & \\
\hline & DATA & char & 0 & \\
\hline & CHECKSUM & int & 1 & \\
\hline & ETX & int & 1 & \\
\hline \multicolumn{2}{|l|}{1} & III & & Q \\
\hline
\end{tabular}

Figure 6. The Data Fields for a Message Frame

\section{Conclusions and Future Work}

VMS has the different sizes and shapes according to the city scene and it has to be displayed by different message on the display panel in real-time. And VMS 
providers must produce the different products each order. In this paper, we design and implement the variable message frame generator system which can set several parameters easily on the Windows environment and the manufacturer of VMS do not need to go the field or data center to get the test variable message frame. In order to generate the variable message frame, we must get the data field $\mathrm{N}$ correctly from the given message frame. The exact message size is decided when the message is generated. And the variable message generator can decide the exact message size using the difference between a given data size and a field of the data size. The emulator system for variable message signs is composed of client/server model. The client is various information services panel such as VMS and PMS and the server is for controlling the system and it has the seven functions which are a message processor, a message generator, a message sender, a job configurator, a job scheduler, a message configurator, and a message logger. In the future work, we will study the real-time scheduling method for the VMS emulator.

\section{Acknowledgements}

This work (Grants No. C0146186) was supported by Business for Cooperative R\&D between Industry, Academy, and Research Institute funded Korea Small and Medium Business Administration in 2013. And this paper is a revised and expanded version of a paper entitled "Development of the Automatic Variable Message Generation System for VMS" presented at NGCIT2014, Hochiminh (Vietnam), 24-26, Oct., 2014.

\section{References}

[1] http://en.wikipedia.org/wiki/Intelligent_transportation_system\#Emergency_vehicle_notificati on_systems.

[2] http://en.wikipedia.org/variable-message_sign

[3] Operations office of travel management, "Changeable Message Sign Operation and Messaging Handbook," Federal Highway Administration, (2009).

[4] Y. J. Joo, C. H. Ham, "Quality Control Scheme of GIS - based Bus Network for Stabilization of BIS - Focusing on Real-time Public Transportation Information “, Journal of KOGSIS, Vol. 20, No. 1, pp. 33-41, (2012).

[5] O. H. Kwon, Y. L. Jang, S. Y. Go, S. G. Baik, "The Development of Traffic Information Service System for Underground Highway", Proc. 2011, No. 2, pp. 165-171, (2011).

[6] J. H. Kim, H. Jin, S. C. Kim, "Design of Adaptive Vehicular Agents Model”, International Journal of Control and Automation, Vol. 7, No. 7, pp. 415-422, (2014).

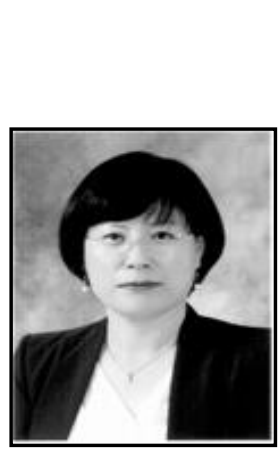

\section{Author}

Jung-Sook Kim, received the B.S., M.S., and Ph.D. degrees in computer engineering from Dongguk University, Seoul, Korea in 1993, 1995 and 1999, respectively. She is a professor in department of multimedia at Kimpo College. Her research interests include in the fields of intelligent systems, IT convergence, and distributed and parallel system. 